at the lower limits of the range for each age-and-sex group, but many patients with severe stenosis have kidneys of normal weight. Moreover, renal weight shows a progressive decrease with age in the absence of renal stenosis. These results pose two questions which at present cannot be answered: firstly, the severity of stenosis necessary to produce a significant reduction in renal blood flow ; and, secondly, whether atrophy is an essential response to renal ischaemia. When other parameters of renal size are considered-namely, polar length and cortical thickness (Figs. 5-8)-essentially similar relations between age and the presence and severity of renal artery stenosis are apparent. From a clinical and radiological viewpoint, it should be noted that if $9 \mathrm{~cm}$. is taken as the lower limit of normal for polar length, then an extremely small proportion of kidneys with severe renal stenosis will be detected. In establishing standards of radiological normality age is obviously an important factor.

The extent of renal cortical scarring has been found to increase with age in both males and females, showing a marginal and inconsistent relation to the presence and severity of renal artery stenosis (Figs. 9 and 10). When only large scars $(1 \mathrm{~cm}$. or greater) are considered, a similarly inconclusive relation with renal stenosis was found. It is suggested that disease of the small cortical arteries, and/or infection, as in pyelonephritis, are more likely to be important in the genesis of cortical scarring than stenosis of the extrarenal and main intrarenal arteries.

\section{Summary}

The frequency, severity, and location of renal arterial stenosis, in both the extrarenal and intrarenal arteries, have been determined in 154 patients comprising an unselected hospital necropsy sample, using the techniques of injection, serial section, and clearing. Severe renal stenosis was found to be bilateral in approximately half of the patients. Intrarenal stenosis of a severe grade was much more common in women than in men, and in the presence of severe extrarenal stenosis occurred with a frequency of $10-18 \%$ in males and $27-36 \%$ in females. No clear or consistent relation between the presence and severity of renal stenosis and the diastolic bloodpressure levels was found when the age of the patients was considered. It is suggested that the marginal differences could be the result and not the cause of elevated blood-pressure levels.

Kidney weight, polar length, and cortical thickness decrease with age in the absence of renal arterial stenosis, and only a small number of kidneys show a significant reduction in these parameters in association with severe stenosis. Renal cortical scarring was found to show but little relation to the calibre of the extrarenal and main intrarenal arteries, although its severity showed a definite increase with age.

We thank Professor J. S. Robertson and the staff of the Adelaide University Department of Pathology for their co-operation, Miss Vija Vainickis for invaluable technical assistance, and Mr. W. Nolan and A. J. Smith for photographic preparation of the figures.

\section{REFERENCES}

Blackman, S. S. (1939). Bull. Fohns Hopk. Hosp., 65, 353.

Braasch, W. F. (1942). Canad. med. Ass. 7., 46, 9.

Eyler, W. R., Clark, M. D., Garman, J. E., Rian, R. L., and Meininger. D. E. (1962). Radiology, 78, 879.

Goldblatt, H., Lynch, J., Hanzal, R. F., and Summerville, W. W. (1934)

F. exp. Med., 59, 347. Path. Bact., 64, 103.

Holley, K. E., Hunt, J. C., Brown, A. L., Kincaid, O. W., and Sheps, S. G. (1962). Circulation, 26, 731.

Janeway, T. C. (1909). Proc. Soc. exp. Biol. (N.Y.), 6, 109.

Kincaid-Smith, P. (1961). Aust. Ann. Med., 10, 166.

Lisa, J. R., Eckstein, D., and Solomon, C.' (1943). Amer. 7. med. Sci., 205, 701 .

Mitchell, J. R. A., and Schwartz, C. J. (1964). Arterial Disease. Blackwell, Oxford. In press.

Rich and Zinger, A. (1964). Brit. med. 7., 1, 205.

Richardson, G. O. (1943). F. Path. Bact., 55, 33.

Schwartz, C. J., and Mitchell, J. R. A. (1961). Brit. med. F., 2, 1057 (1962a). Brit. Heart f., 24, 761.

Smith (1962b). Circulat. Res., 11, 63.

Sutton, D. Brunton, F. Urol., 76, 685. F. (1961). Clin. Radiol., 12, 80

World Health Organization (1958). Techn. Rep. Ser., No. 143.

\title{
Causes and Prevention of Domestic Burning Accidents
}

\author{
J. P. BULL,* M.D. ; D. M. JACKSON,* M.D., F.R.C.S. ; CYNTHIA WALTON,* B.SC.(ECON.)
}

Brit. mod. F., 1964, 2, 1421-1427

In the eight years since the last review from the Birmingham Burns Unit of the causes and prevention of burns (Colebrook et al., 1956) there have been important legislative and social changes. The Heating Appliances (Fireguards) Act, 1952, which requires all gas and electric fires to be guarded when sold has been in force; British Standards have been introduced for ordinary fireguards (B.S.2788), for nursery fireguards (B.S. 3140), for flammability of fabrics (B.S.3120 and B.S.3121), and for paraffin heaters (B.S.3300). The Oil Burners (Standards) Act, 1960, requires that all oil fires must comply with new safety standards. Improved flame-resistant fabrics and garments have been on the market, and since 1961 there has been a testing scheme for safe nylon nightwear.

General changes in social habits include the increased use of gas and electric convector fires and the trend towards central heating, both of which might be expected to reduce accidents from burns. This, however, may have been offset by the in-

- Medical Research Council Industrial Injuries and Burns Research Unit, Birmingham Accident Hospital. creased use of portable oil-burning heaters, particularly those made before 1960 . It is therefore appropriate to examine what changes have occurred in the numbers and types of burning accidents and in the availability and application of methods of prevention.

\section{Incidence of Burning Accidents}

The Registrar-General's figures for deaths from burns and scalds since 1955 are summarized in Table $I$. These figures show somewhat reduced numbers of deaths among children under 15 years, an appreciable increase in those aged 15-64, and a continuing large number of deaths in people of 65 years and over. During the eight-year period there has been an increase of $5 \%$ in population, particularly marked in the $65+$ age-group, which has increased by $12 \%$. When the figures in Table I are corrected for the population at risk, young children (0-4 years) show a fairly steady death rate from burns of about 29 per million at risk per annum. Both boys 
and girls aged 5-14 years have a slightly decreasing death rate, averaging about 7 per million. The rate for persons aged 15-64 has increased from about 7 per million in 1955 to about 9 in 1962. In persons 65 years old and over the overall rate has risen slightly to about 80 per million, the increase being more pronounced among women than among men. Deaths from scalds account for about one-tenth of the number due to burns, and have tended to decrease in all age-groups. The main change in mortality has therefore been an increase of deaths in persons aged 15-64. In spite of all efforts at prevention, total deaths per annum have increased slightly, though this increase is not marked when corrected for increase of population.

The recorded causes of deaths from burning accidents in England and Wales are summarized in Table II. Deaths due to clothes catching fire are slightly lower, in spite of the rising population, as are also deaths attributed to falling into fires.

TABLE I.-Deaths from Burns and Scalds (England and Wales)

\begin{tabular}{c|c|c|c|c|c}
\hline Year & $0-4$ years & $5-14$ years & $15-64$ years & $65+$ years & All Ages \\
\hline 1955 & 111 & 71 & $197 *(54)$ & $438(5)$ & $817(59)$ \\
1956 & 110 & 57 & $213(85)$ & $442(7)$ & $822(92)$ \\
1957 & 94 & 44 & $230(76)$ & $368(4)$ & $736(80)$ \\
1958 & 107 & 58 & $187(50)$ & $417(2)$ & $769(52)$ \\
1959 & 97 & 59 & $202(62)$ & $448(4)$ & $806(66)$ \\
1060 & 95 & 49 & $219(39)$ & $367(3)$ & $730(42)$ \\
1961 & 80 & 35 & $267(96)$ & $401(1)$ & $783(97)$ \\
1962 & 107 & 50 & $267(79)$ & 483 & $907(79)$ \\
\hline
\end{tabular}

- Including burns at work; numbers shown in parentheses.
These decreases are more than offset by increases in deaths attributed to conflagrations and to other unspecified causes. It should be noted that these attributions are exclusive in the sense that a death can be attributed to only one of the causes. It is, however, common for persons who fall into open fires or who are exposed to conflagrations also to suffer burns from their clothing catching fire. In our analysis of cases admitted to the Burns Unit we have grouped together cases in which clothes caught fire, regardless of the source of ignition. This is consistent with the lower proportion of fatalities attributed to clothes catching fire in the Registrar-General's statistics (about one-half) as compared with those of the Birmingham series (about four-fifths).

\section{Domestic Burns and Scalds in Birmingham}

In the period July 1955 to December 1962, inclusive, 2,054 patients were admitted to the Burns Unit because of burning or scalding accidents which occurred at home. Domestic burns sccounted for 1,322 cases (two-thirds of the total), with a case mortality rate of $14 \%$. Domestic scalds accounted for 732 accidents, with a case mortality rate of $1.6 \%$.

\section{1,322 Domestic Burns}

The distribution of cases by age, sex, and cause of accidents is shown in Table III. The yearly average of cases of domestic

TABLE II.-Causes of Fatal Burns and Scalds (England and Wales)

\begin{tabular}{|c|c|c|c|c|c|c|c|c|c|c|c|c|c|c|c|c|}
\hline & \multicolumn{2}{|c|}{1955} & \multicolumn{2}{|c|}{1956} & \multicolumn{2}{|c|}{1957} & \multicolumn{2}{|c|}{1958} & \multicolumn{2}{|c|}{1959} & \multicolumn{2}{|c|}{1960} & \multicolumn{2}{|c|}{1961} & \multicolumn{2}{|c|}{1962} \\
\hline & $M$ & F & $M$ & F & $\mathbf{M}$ & $\mathrm{F}$ & $M$ & F & $\mathbf{M}$ & $\mathbf{F}$ & $\mathbf{M}$ & $\mathbf{F}$ & $\mathbf{M}$ & F & $\mathbf{M}$ & $\mathbf{F}$ \\
\hline Clothes caught fire $\left\{\begin{array}{l}\text { Coal-fire } . . \\
\text { Gas-fire } . \\
\text { Electric fire } \\
\text { Other } \quad .\end{array}\right.$ & $\begin{array}{r}19 \\
9 \\
7 \\
42\end{array}$ & $\begin{array}{r}120 \\
41 \\
57 \\
72\end{array}$ & $\begin{array}{r}21 \\
2 \\
3 \\
36\end{array}$ & $\begin{array}{r}114 \\
39 \\
50 \\
94\end{array}$ & $\begin{array}{r}10 \\
4 \\
5 \\
33\end{array}$ & $\begin{array}{r}101 \\
42 \\
44 \\
74\end{array}$ & $\begin{array}{r}16 \\
4 \\
7 \\
40\end{array}$ & $\begin{array}{r}112 \\
33 \\
45 \\
75\end{array}$ & $\begin{array}{r}18 \\
4 \\
7 \\
47\end{array}$ & $\begin{array}{l}85 \\
39 \\
57 \\
86\end{array}$ & $\begin{array}{r}11 \\
1 \\
3 \\
35\end{array}$ & $\begin{array}{l}81 \\
25 \\
47 \\
86\end{array}$ & $\begin{array}{r}7 \\
2 \\
10 \\
36\end{array}$ & $\begin{array}{l}75 \\
15 \\
39 \\
65\end{array}$ & $\begin{array}{r}12 \\
6 \\
5 \\
34\end{array}$ & $\begin{array}{l}80 \\
24 \\
65 \\
98\end{array}$ \\
\hline 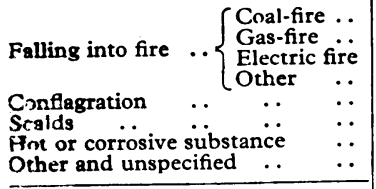 & $\begin{array}{r}39 \\
2 \\
4 \\
3 \\
48 \\
39 \\
26 \\
84\end{array}$ & $\begin{array}{r}34 \\
1 \\
7 \\
15 \\
56 \\
33 \\
27 \\
32\end{array}$ & $\begin{array}{r}19 \\
2 \\
2 \\
19 \\
55 \\
33 \\
37 \\
74\end{array}$ & $\begin{array}{r}20 \\
1 \\
15 \\
52 \\
49 \\
31 \\
55\end{array}$ & $\begin{array}{r}21 \\
2 \\
2 \\
3 \\
60 \\
33 \\
19 \\
92\end{array}$ & $\begin{array}{r}19 \\
1 \\
5 \\
4 \\
74 \\
37 \\
17 \\
34\end{array}$ & $\begin{array}{r}27 \\
2 \\
5 \\
1 \\
45 \\
44 \\
32 \\
79\end{array}$ & $\begin{array}{r}32 \\
2 \\
2 \\
2 \\
34 \\
41 \\
22 \\
67\end{array}$ & $\begin{array}{r}24 \\
3 \\
2 \\
2 \\
50 \\
32 \\
20 \\
111 \\
\end{array}$ & $\begin{array}{r}28 \\
5 \\
4 \\
2 \\
43 \\
50 \\
14 \\
73\end{array}$ & $\begin{array}{r}29 \\
2 \\
4 \\
1 \\
57 \\
25 \\
22 \\
85\end{array}$ & $\begin{array}{r}37 \\
2 \\
1 \\
5 \\
58 \\
28 \\
14 \\
71\end{array}$ & $\begin{array}{r}24 \\
1 \\
3 \\
77 \\
39 \\
27 \\
137\end{array}$ & $\begin{array}{r}36 \\
4 \\
7 \\
3 \\
63 \\
25 \\
13 \\
75\end{array}$ & $\begin{array}{r}22 \\
9 \\
2 \\
99 \\
24 \\
22 \\
126\end{array}$ & $\begin{array}{r}31 \\
1 \\
7 \\
1 \\
85 \\
38 \\
14 \\
102\end{array}$ \\
\hline Total & 322 & 495 & 303 & 519 & 284 & 462 & 312 & 467 & 311 & 486 & 275 & 455 & 363 & 420 & 361 & 546 \\
\hline
\end{tabular}

TABLE III.-Distribution of Home Burns in Relation to Nature of Accident (Deaths Shown in Parentheses)

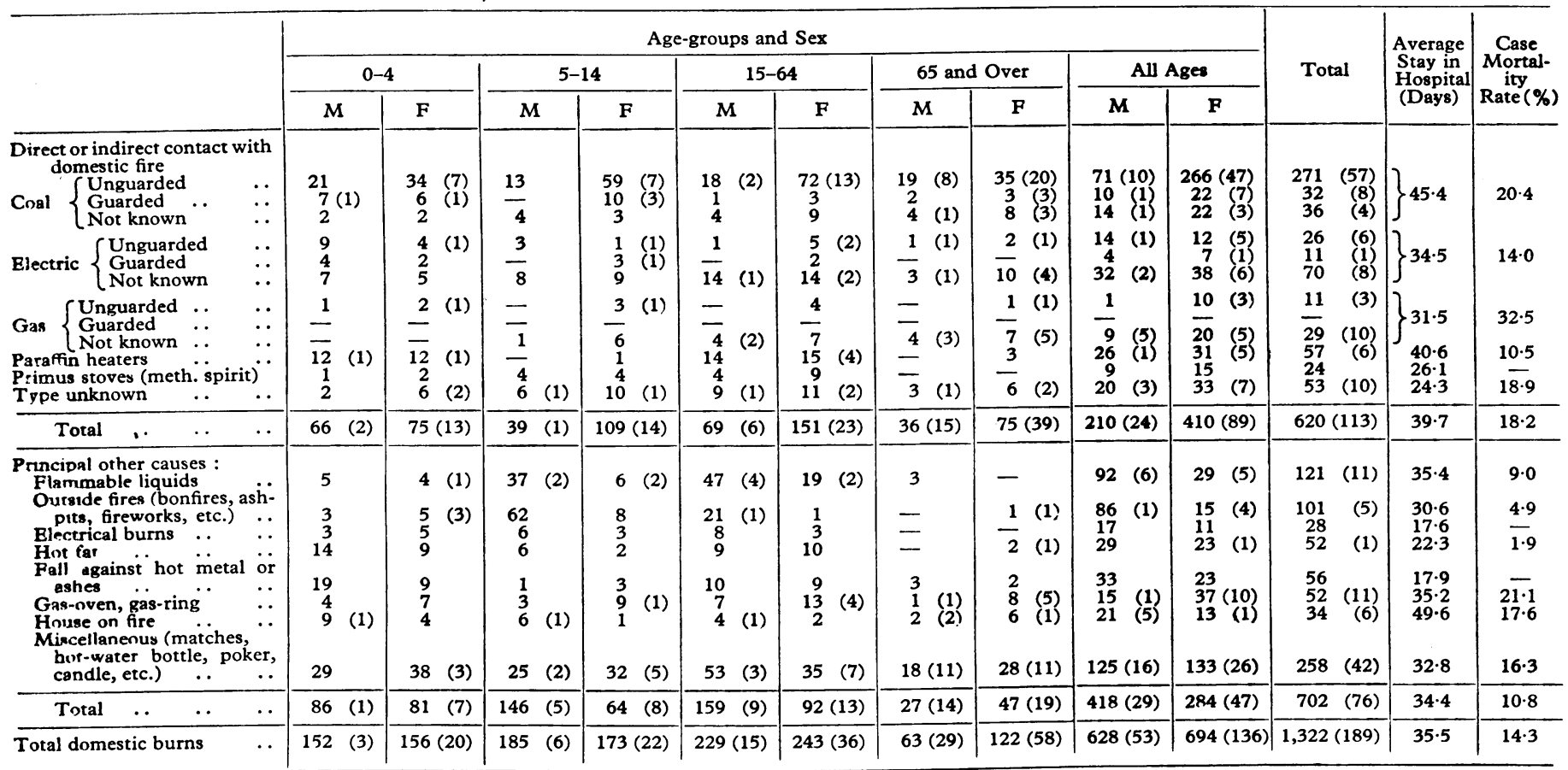


burns admitted to the Burns Unit has increased from 155 in in the last series to 176 in this series. The number of accidents occurring to children under 15 and to adults of 65 and over has remained constant, but for those aged 15-64 the number of cases and the mortality rate have increased, which mirrors the national mortality trend.

Keeping the home fires burning had tragic consequences for many people: 620 cases, or just under half the total, were due to direct or indirect contact with domestic heating appliances. At all ages females were involved twice as often as males, with almost four times the mortality rate. There has been an increase in cases involving females aged 15-64; previously they accounted for one-sixth of all cases-now they account for one-quarter. On the other hand, accidents to children aged 5-14 have dropped to $24 \%$ (109 girls, 39 boys), compared with $32 \%$ (85 girls, 27 boys) in the last series.

Our traditional symbol for warmth and security-the unguarded open coal-fire-still holds the record as the biggest single cause of accidents and deaths due to heating appliances. In the present series it caused $44 \%$ of accidents due to heating appliances (an increase from $37 \%$ in the last series) and $50 \%$ of the deaths. Accidents due to unguarded electric fires have shown a dramatic fall from $24 \%$ in the last series to only $4 \%$ in the present study. This seems almost certainly due to the effect of the 1952 Fireguards Act; there is also a downward trend in the national figures (Lawson, 1964). Accidents due to unguarded gas-fires also show a decline from $9 \%$ to $2 \%$, although the cases for 1962 show an unexpected rise in number. In Table III two new categories of heating appliances have been listed separately-paraffin heaters and primus stoves. Together they caused $12 \%$ of the accidents and $5 \%$ of the deaths.

In the 702 burns accidents not associated with the domestic hearth, males predominated with $60 \%$ of the cases. The two biggest single causes of accidents at all ages were flammable liquids, mainly petrol and paraffin, and outside fires-both showing an increase from the previous series. Flammable liquids cause $30 \%$ of the accidents to males aged 15-64. Outside fires, which include bonfires, rubbish dumps, and fireworks, were the cause of nearly half the accidents to boys aged 5-14 -that is, almost double the previous figures for this cause ; but there is a relatively low mortality rate of under $5 \%$ associated with this type of accident. Firework burns call for special mention in view of the nation-wide study of this type of injury started by the Home Office in 1962 . There were 72 admissions for firework burns in the eight Guy Fawkes celebrations covered by this review. Males predominated in the proportion $23: 1$, and most of the injured were between 10 and 30 years old. Fireworks going off in the pocket and burning the thighs (53 cases) accounted for three-quarters of all the cases, and, although the majority had their clothes alight, the fireworks themselves were probably responsible for most of the damage. These firework injuries caused a mean in-patient stay of 25 days, and together cost the hospital service 1,849 bed-days.

Many of the accidents in females centred on the cookingstove and oven, but other domestic chores were also shown to be hazardous, especially ironing and the stoking and cleaning of the solid-fuel fire. Several accidents were due to "safe" central heating, when the patient fell against or touched hot-water pipes and hot radiators.

About $40 \%$ of the accidents were due to a large variety of causes and have been grouped under one heading. One-fifth of the accidents in this group were due to matches and smoking materials: one-sixth were due to ignited materials, ranging from an explosion with a hair-dressing process to a flaming Christmas-tree.

Although conflagrations are not very prominent as a cause of burns requiring admission to hospital, in the present series the proportion has increased from $1.7 \%$ to $4.9 \%$, which confirms the national trend.

\section{Domestic Scalds}

The annual average of scalded patients admitted to the Birmingham Burns Unit remained the same as in the previous period. The distribution by age, sex, and type of accident is shown in Table IV. Children were the chief victims, and accounted for $80 \%$ of all cases as in the previous series ; seven out of eight of these children were under 5 years old. Children aged 5-14 had a relatively high risk as compared with persons of 15-64. Boys were involved in scalding accidents more often than girls-in the 0-4 age-group three out of five cases were boys.

The overall case mortality from scalds has dropped from $2.4 \%$ to $1.6 \%$ in the present series, and is low compared with that for burning accidents. The highest case-mortality rate, $4.7 \%$, was associated with the extensive scalds due to children falling into buckets or baths of boiling water. Such accidents might be avoided if greater care were taken to run baths at the temperature required; but this is still difficult where a tub is filled with kettles of hot water from a gas-ring. Accidents due to spills from containers of hot water-mostly kettles and saucepans-have dropped in the present series from $35 \%$ to $25 \%$, with a case mortality of $1.6 \%$. Accidents due to the national beverage have increased from $19 \%$ to $26 \%$, but there were no fatalities associated with tea.

\section{Accidents During Unconsciousness}

Colebrook and Colebrook (1949) noted that $16 \%$ of the adults receiving burns and scalds at home were injured in an epileptic fit ; Jackson (1953) found that $16 \%$ of the fatal burns in the Birmingham Unit in 1948-52 occurred during unconsciousness ; in a study by Tempest (1956), in South Wales, epileptice formed $7 \%$ of those sustaining domestic burns and scalds; and Maisels and Corps (1964), working mostly with adults, foun $\$$ $14 \%$ of their domestic cases due to this cause.

In the present series of 2,054 domestic burns and scalds, $10 \gamma$ injuries $(5 \%)$ were sustained in an epileptic fit (Table V), and about six-sevenths were in persons aged 15-64. The number of epileptics at risk in the 0-14 age-group is smaller than in adults-only a quarter of the population being in this age-group and only half the cases of epilepsy developing before the age of 15 ; but the rarity of burns among epileptic children suggests that effective care is being taken to prevent such injuries.

TABLE IV.-Distribution of Home Scalds in Relation to Nature of Accidents (Deaths Shown in Parentheses)

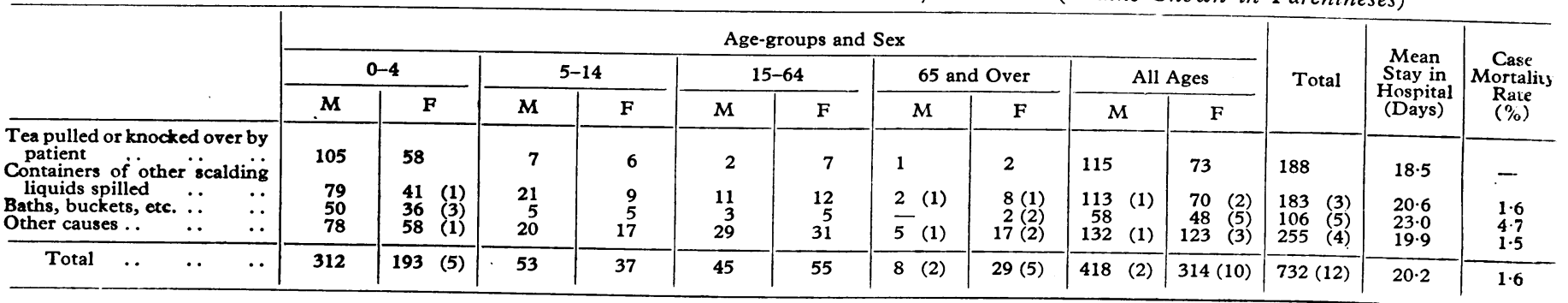


Most of the injuries were burns, often from falling into an unguarded fire or against a hot object. The relatively few scalds (15) were predominantly in women, and were related to cooking and other household tasks. Apart from these scalds injuries related to epilepsy were fairly evenly divided between the sexes.

TABLE V.-Burns and Scalds During Unconsciousness (Deaths Shown in Parentheses)

\begin{tabular}{|c|c|c|c|c|c|c|}
\hline \multirow{2}{*}{$\begin{array}{l}\text { Age in } \\
\text { Years }\end{array}$} & \multicolumn{3}{|c|}{ Epilepsy } & \multicolumn{3}{|c|}{ Other Unconsciousness } \\
\hline & Male & Female & Total & Male & Female & Total \\
\hline $\begin{array}{cc}0-14 & \cdots \\
15-64 & \because \\
55+ & \because\end{array}$ & $\begin{array}{r}1 \\
37 \\
3\end{array}$ & $\begin{array}{rr}0 & \\
55 & (2) \\
11 & (1)\end{array}$ & $\begin{array}{rr}1 & \\
92 & (2) \\
14 & (1)\end{array}$ & $\begin{array}{r}4 \\
18 \\
18\end{array}$ & $\begin{array}{rr}0 & \\
26 & (2) \\
17 & (5)\end{array}$ & $\begin{array}{cc}4 & \\
44 & (2) \\
35 & (5)\end{array}$ \\
\hline Total & 41 & 66 (3) & 107 (3) & 40 & 43 (7) & $83(7)$ \\
\hline
\end{tabular}

Other causes of unconsciousness were responsible for another $83(4 \%)$ accidents. Many of these attacks were incidents in chronic conditions such as diabetes (10 cases) or "blackouts," "faints," and "giddy attacks" in neurological disorders and cardiovascular disease.

Burn injuries associated with unconsciousness are usually not extensive, but they are deep owing to prolonged contact with the source of heat; they are often down to the bone. Three of the burns due to epilepsy were fatal, as were seven of the burns due to other causes of unconsciousness; the high figure was to be expected from the associated disease causing the attacks.

\section{Clothes Catching Fire}

Ignition of clothing causes deep and large burns, and accidents in which clothes catch fire are still the main cause of fatal injuries-90\% of the deaths from domestic burns in Birmingham were due to the ignition of clothing, an even higher proportion than in the previous study. Accidents where clothing caught fire accounted for more than half of all inpatient admissions to the Burns Unit, and the proportion rose both for males (from $31 \%$ to $43 \%$ ) and for females (from $64 \%$ to $68 \%$ ) (Table VI).

At all ages females were much more often involved than males in accidents where clothes ignited, and this preponderance was particularly marked in the very young and the very old. Among females the main increase in the proportion of burns due to this cause has been in those aged 15-64 (from $47 \%$ to $57 \%$ ). Two-thirds of the accidents to females involving clothes catching fire were caused by contact with a domestic heating appliance.

For males the main increase in accidents involving ignition of clothing came in those aged 5-14 (from $34 \%$ to $55 \%$ ) and in those aged $15-64$ (from $33 \%$ to $41 \%$ ). These accidents were mainly associated with activities outside the home. Threequarters of such accidents to males between 5 and 64 years were caused by outside fires, matches, flammable liquids, and fireworks.

Burns associated with clothes catching fire were responsible for all the fatal burns in children. The total case mortality for clothing burns remained about $23 \%$, in contrast with $3 \%$ for other burns. The particularly high rate in the elderly, $73 \%$ for persons of 65 and over, accounts for the apparent discrepancy between the preponderance of old persons in national figures for deaths from burns (Table I) and the high proportion of young persons among hospital admissions (Table III).

The style of clothing decreed by custom and fashion is an important factor in determining the risk, flowing skirts being particularly dangerous.' In Birmingham out of 424 known garments which first ignited the two most common were dresses $189(45 \%$ of total) and nightdresses 102 (24\% of total) (Table VII). Accidents due to nightdresses catching fire have decreased from an average of 22 a year to 14 , while accidents due to dresses being set alight have increased from 16 a year to 25 a year. Accidents due to pyiamas catching fire have not changed $(4 \%)$, and caused only one fatality in the present series. It is interesting that accidents involving trousers now account for $20 \%$ of the total-half of these were due to fireworks, many known to have been set alight in pockets.

The fabric of which clothes are made largely determines the risk of burning accidents. Out of 131 cases where the fabric was known, 100 garments first ignited were cotton $(76 \%)$ and 17 were winceyettes or flannelettes (13\%).

There are two ways of preventing these accidents-one is the better guarding of fires; the other the provision of flameresistant clothing. In the past few years progress has been made in both these directions.

TABle VI.-Home Burns Associated with Clothes Catching Fire (Deaths Shown in Parentheses)

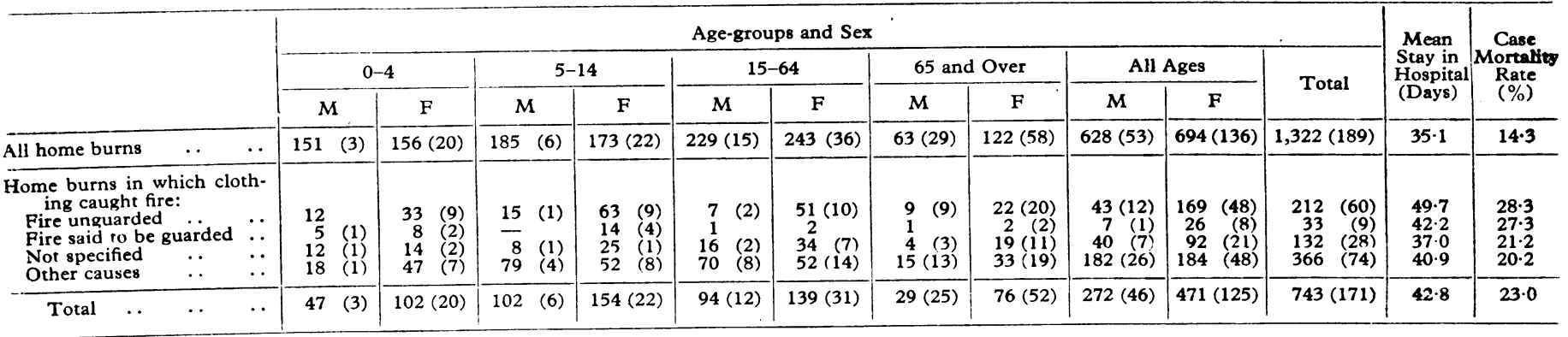

TABLE VII.-Garments Ignited in 743 Clothing Burns (Deaths Shown in Parentheses)

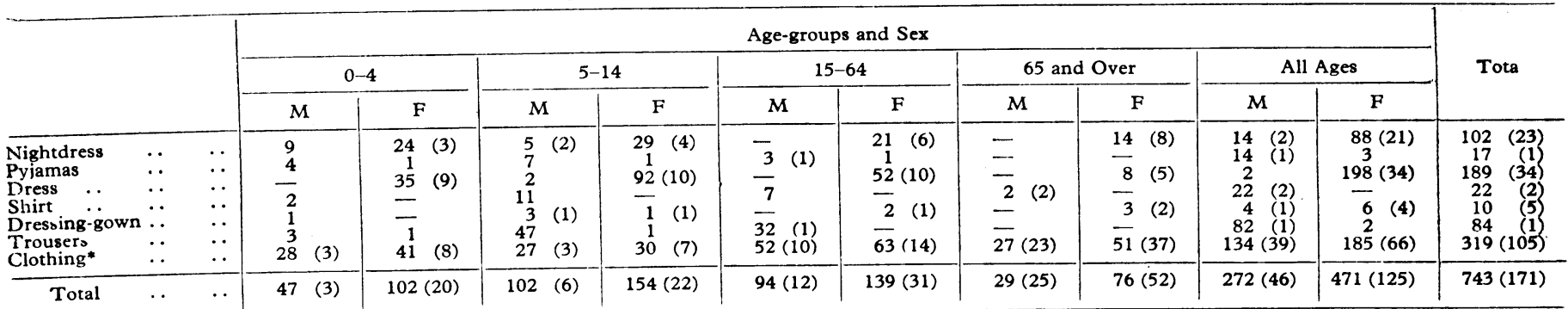

*In the cases included under "Clothing" the records did not give precise information (sometimes it was unobtainable) regarding which garment wes the first to be ignited. 


\section{Guarding of Fires}

\section{Open Coal-fire}

The Children and Young Persons Act made it an offence to leave a child of 7 or under with an unguarded coal-fire. In 1952 this Act was amended to include children of up to 12, and all heating appliances. This Act is rarely brought to the notice of the general public by publicity in the press or in shops where such regulations on display could be used as a selling aid for fireguards. Penalties are seldom invoked under the Act. The fact that a guard was not in use is usually discovered only after a tragic burning accident to a child ; then it is usually considered that the parents have been punished enough.

Continuing concern about the inadequate guarding of coalfires led to the drawing up of two British Standards in 1956B.S.2788 and B.S.3140. B.S.2788 was for guards which cover the fire aperture, while B.S.3140 was for nursery guards which cover the whole fireplace. Both standards stipulated a small mesh of $\frac{3}{4}$ in. $(2 \mathrm{~cm}$.) and hooks at the side of the guard which can be fitted into eyelets in the fireplace or surround, and so hold the guard firmly in position. Doors that open (B.S.2788) or a hinged top (B.S.3140) were specified for refuelling.

Some local authorities supply guards free of charge in cases of social or economic need or sell guards at a reduced price to Council tenants. Edinburgh has a scheme whereby guards can be hired for a nominal sum; London County Council loans fireguards to needy cases recommended by the health authorities. In Birmingham there is a similar scheme, and a local health visitor estimates that she provides one family a week in her area with a guard in this way. In Birmingham approved guards are on sale by the Corporation to its tenants12s. 6d. if collected and 16s. 6d. if delivered. In 1963, 599 people bought guards by this method.

Many fireguards on sale are of flimsy construction or not capable of being firmly fixed to the fireplace. Often parents say that a guard was in place when they left the room but that the child had removed it himself. Other accidents are caused by elderly people and children falling against a guard, which either collapses or is pushed to one side. A recent survey (Birmingham Consumer, 1964) showed that the majority of guards on sale are either cheap spark guards or the flimsy folding guard with wide-aperture mesh. Neither of these guards can fully protect the old or children from the dangers of coalfires.

There are guards made to British Standards-Why do people not buy them ? The answer is threefold: availability, price, and difficulty of fixing. In Birmingham in January 1964 (Birmingham Consumer, 1964), of 50 shops selling fireguards, only 19 stocked a B.S. guard, although there was at least one shop in each area stocking such guards. The smaller the shop the less likely was the shopkeeper to stock B.S. guards, and many of the ironmongers had never heard of B.S. specifications or else stated roundly that all their guards on sale came up to British Standards. There are at present eight manufacturers making guards to B.S.2788 and B.S.3140. In 1963 several mail-order firms had such guards in their catalogues. Although availability is fair there is no doubt that a shopper might have to visit two or three shops or take the trouble to order a guard by post before she can get exactly what she needs.

The price of B.S. guards is an important factor in poorer households. The cheapest guard to B.S.2788 costs 20s. 9d., compared with the cheapest spark guard at 6s. 11d. Nursery guards to B.S.3140 are even more expensive, ranging from $47 \mathrm{~s}$. to $79 \mathrm{~s}$., according to size. If demand increased perhaps the price could be brought down to a figure which would not deter the family with a small income.

Possibly the biggest difficulty concerns fixings. B.S.2788 requires eyelets to be fixed into the fireplace surround. Many people with nicely tiled fireplaces do not care to risk spoiling them by drilling holes for eyelets. One solution is for the eyelets to be built into the fireplace when a new house is being built-the cost is estimated at $6 \mathrm{~d}$. Some corporations-London, Manchester, Birmingham, and others-have for some years specified the building in of fireplace eyelets as a standard feature in new corporation dwellings. Birmingham will supply and Crawley will also fit eyelets in fireplaces of older corporation houses free of charge. The demand for nursery guards to B.S.3140 has been greater, probably owing to the fact that eyelets can be more simply fixed into the wall at the side of the fireplace. In Birmingham out of 19 shops selling B.S. guards, 18 stocked the nursery guard. There is now an adjustable nursery fireguard on sale which fits hearths of any length and which is proving popular with the public.

To get over the problem of eyelets another method of fixing is needed. There are already two such guards on the market, both with features conforming to those stipulated by British Standards, with small mesh and doors that open. They depart from the Standard in that the guard is fixed by means of spring hooks which reach into the top of the fireplace aperture. At the moment the price of these guards is high-about 12 - but neither publicity nor production is on a large scale. There seems scope for modification of the British Standard to include such guards and for encouragement of their use where guards with eyelets are impracticable.

\section{Guarding of Gas and Electric Fires}

The Heating Appliances (Fireguards) Act, 1952, came into force in 1954. It requires that all gas and electric fires must be sold already guarded in accordance with B.S.3456. Now that this Act has been in force for 10 years there seems little doubt from both national and Birmingham figures that it has helped in reducing the number of accidents from gas and electric fires and has thus accomplished much of what it set out to do.

However, there is still a risk with fires guarded in this way. The mesh is so wide that children can poke paper or other flammable material through it, and such a guard could not prevent an accident if an old person fell against the guard and stayed against it for more than a few seconds. The British Standard specification states: "The present standard is restricted to providing protection to persons and property from accidents such as may arise through negligence and thoughtlessness on the part of able adults. Fires complying with this British Standard are not suitable, without further protection, for use in rooms occupied by unattended young children or aged or infirm people."

This is not generally known, and many people buy such guarded fires and, without extra precautions, put their children or themselves at risk. A warning label about the limited safety of such guards should be fixed on new fires, and the consumer might have the alternative of a guard more appropriate for children and old people.

There must also still be a considerable number of old gas and electric radiant fires in use which were manufactured and bought before the Fireguards Act came into force. It used to be possible to buy guards at electricity and gas showrooms that could be fitted to old fires. In 1964, however, the Birmingham Consumer Group found few guards on display and had difficulty in obtaining the patterns required.

\section{Oil Fires}

Under the 1952 Fireguards Act radiant oil fires must be guarded in a similar way to gas and electric fires, and the problem of the present wide mesh applies to them also.

The main danger of oil heaters, however, has been the problem of the unstable drip-feed fire which could cause accidents due to draughts and toppling over of the heater (Fire 
Research, 1960). Our series includes several very severe injuries due to this type of appliance.

The Oil Burners Standards Act 1960 and Regulations (1962) under the Consumer Protection Act dealt with both these dangers, so that oil burners now on sale are much safer than earlier models. Nevertheless a free-standing appliance which contains its own fuel, particularly where the fuel is fed by gravity to the burner, must always be used with caution.

\section{Availability of Safe Clothing}

Our previous survey drew attention to the importance of design of clothing in determining risk of burning injury. The danger of nightdresses made of flammable fabric has been repeatedly emphasized by coroners, consumer and standards organizations, Members of Parliament, and the press. From October 1964 flammable children's nightdresses are banned from the shops, and further legislation is now in progress to give wider protection. The concern by responsible bodies, including that of certain manufacturers and retailers, may already have had a good effect. In our present series the proportion of accidents to children due to ignition of nightdresses has fallen from $48 \%$ to $24 \%$.

However, until late 1963 flammable children's nightdresses were still-made in quantity and sold in chain stores and other shops in all parts of the country. Notable exceptions were Ladybird and Marks \& Spencer, who withdrew such nightdresses from their range some years ago on grounds of safety. In autumn 1963 the Consumer Council appealed to 33 large stores and mail-order houses to refrain from stocking flammable children's nightwear ; only 11 gave the assurances asked for; these included the Lewis Group, Littlewoods, British Home Stores, and Woolworths. In place of girls' winceyette nightdresses these firms then offered a choice of brushed nylon nightwear, flannelette pyjamas, and in some cases proofedcotton nightwear. However, a survey in Birmingham in January 1964 showed that many other shops, particularly in the suburbs, were still selling flammable nightdresses.

There is now promise of progress towards safe nightwear for children. But supply could be improved for adults-especially the aged and infirm. The increased proportion of accidents due to dresses in the Birmingham series shows that there is much scope for safer day wear at all ages.

\section{Fabrics}

It is now well established that cotton fabrics are most commonly involved in burning accidents to women and girls. The increasing use of cotton for trousers and jeans is probably a factor in the increased incidence of similar accidents to men and boys.

New fabrics are constantly introduced, and it is not surprising that there has been some confusion on both sides of the counter about which is or is not safe. Fortunately, appropriate tests are available-for example, B.S.2963-which provide a comparative rating of flammability. Taking the rating of 150 as the limit of "low flammability," pure nylon and Terylene, Nelson's flame-resistant acetate, Teklan, and Proban-proofed cottons are all acceptable. Weight of a fabric is important ; wool fabrics heavier than $8 \mathrm{oz}$. per sq. yd. $(270 \mathrm{~g} . / \mathrm{sq} . \mathrm{m}$.) and Terylene $55 \% /$ wool $45 \%$ mixtures heavier than 5 oz. per sq. yd. (170 g./sq. m.) also pass this test, but no untreated cotton or rayon fabrics of clothing weights are sufficiently flame-resistant.

Although nylon, Terylene, and Teklan are inherently flameresistant, some other man-made fibres such as Orlon, Courtelle, and Acrilan are flammable. If nylon and Terylene are in a fabric mixture with a flammable fibre, that fabric also tends to be flammable. Wool/cotton fabrics are almost as flammable as pure cotton for fabrics of comparable weights. If non- flammable fabrics are edged with flammable trimmings, the trimming can act as a wick and permit dangerous burning.

The Proban flame-resistant finish for cottons was one of the first in the field. The finish is based on a phosphorus compound which is applied to the fabric after the processes of dyeing, printing, and raising have taken place-and such treated fabric cannot support flame. So far this finish has been used on woven cotton fabrics-mainly winceyette-but can now be applied to knitted cottons. In washing, household bleach must not be used as it masks the finish.

The value of nylon as a safe fabric for clothing has been enhanced by the introduction of a testing and labelling scheme by British Nylon Spinners. Finishers of the fabric must provide samples for testing-this is particularly important where patterned fabrics are concerned, as some of the pigments are themselves flammable. If made-up garments are to pass the test flammable thread and flammable trimmings must not be used. All nylon net now manufactured is this country is of "low flammability." When nylon fabric is in contact with flame the edge melts but then recedes from the flame and does not cause extensive burning. The molten drops can cause small local burns, but these are of " nuisance value" compared with the extensive burns caused when flames are propagated by a fabric.

In 1962 a flame-resistant acetate yarn was introduced by the Bradford Dyers Association and Nelson's Silks. Unlike the Proban finish, the proofing agent is built into the yarn. The cellulose is dissolved in tris-2-3 dibromo-propyl phosphate, and the acetate is then spun by the normal dry-spun continuous filament process. This fabric shrinks away and melts when held to a flame. The latest flame-resistant fabric to come on the market is Teklan. This is inherently nonflammable and shrivels away from the source of heat without smouldering or forming molten drops. Made-up garments of both Nelson's acetate and Teklan must pass tests similar in scope to those used by British Nylon Spinners.

Proban-treated fabrics and garments have been available for some years but have never been sold in large quantities. Apathy has been blamed, but relatively high prices and limited availability compared with the large cheap stocks of untreated cottons must have contributed to lack of demand. Although the cost of proofing is only 1s. a yard, the retail price of proofed fabric has been double that of untreated winceyettes with a similar mark up for garments. By direct manufacture and small profit margins only a few firms have been able to offer a range of competitively priced garments.

Good availability of non-flammable nightwear for children has come only since the introduction of non-flare nylon nightwear produced under the quality control scheme of British Nylon Spinners. In autumn 1963 over 60 manufacturing firms were co-operating in this scheme, and chain-stores, mail-order firms, and many others had good stocks of such nightwear in pretty colours and at reasonable prices which have been selling well.

Up to now neither fabric by the yard nor garments made from Nelson's acetate or Teklan have been readily available.

\section{Discussion}

Though there is little evidence yet of a reduction in the total of injuries and deaths from burning accidents, there are several heartening suggestions of favourable results where action has been taken to attack specific parts of the problem.

Legal enforcement of the guarding of new gas and electric fires, elimination of the more dangerous types of oil-burning heaters, and the restriction on sales of flammable nightdresses already seem to have had success in reducing accidents. Though general safety propaganda and publicity doubtless helps, it is probably significant that these successes have involved direct 
action by manufacturers and retailers. In the case of fireguards and oil heaters this was stimulated by Government intervention. Up to the present the action on nightdresses has been voluntary but now has legal backing. Underlying all these developments has been the work on standardization, for which credit is particularly due to the British Standards Institution and the Fire Research Station. Consumer organizations have also helped in producing an informed public demand for safer products.

Another example of successful control by manufacturers was the substitution in 1957 of the explosive "thunder flash" type of firework by a less dangerous "banger." This resulted in reduction by two-thirds of the injuries due to these fireworks being (wrongly) held in the hand (Jackson, 1961). However, it is hard to see how the majority of firework accidents can be prevented unless explosives are kept entirely out of the hands of children and high-spirited teenagers.

In the light of the modest successes already achieved it should be possible to tackle the remaining problems. These include the more thorough guarding of open fires, provision of safe nightwear for the elderly and infirm, and safer daywear, particularly for girls and women, though the relative immunity of males has been reduced with the introduction of unproofed cottons and celluloses for trousers. New hazards also may increase in importance-for instance, accidents with flammable liquids are becoming more frequent, as also are deaths from conflagration. These present new challenges to research into details of causes and prevention.

\section{Summary}

Since the previous survey eight years ago both annual deaths from burns and admissions to the Burns Unit have increased. The main increases have been among persons aged 15 to 65 years.
Just under half the cases in Birmingham were due to direct or indirect contact with domestic heating appliances. The unguarded open coal-fire was responsible for almost half of the accidents due to these causes and half of the deaths.

Accidents due to unguarded electric fires have shown a dramatic fall from $24 \%$ to $4 \%$ in the present study. There is also a downward trend in the national mortality figures due to this cause.

Ignition of flammable liquid causes an increasing number of injuries to schoolboys and men.

Accidents where clothing caught fire caused $90 \%$ of the deaths, but there has been a change in emphasis in the present Birmingham series. The accidents due to children's nightdresses catching fire have fallen by half and are outnumbered by those due to the ignition of dresses. Accidents involving clothing of females aged 15-64 are now more common. There has also been an increase in accidents in which trousers caught fire.

Cotton fabrics were involved in four-fifths of accidents where clothes caught fire.

Preventive action has had success in improved guarding of gas and electric fires, elimination of the more dangerous oil burners, and encouragement of safer nightwear for children.

Further action is recommended for improved guarding of open fires and the wider use of safe fabrics for both day and night wear.

REFERENCES

Birmingham Consumer, 1964, 4, 29.

Colebrook, L., and Colebrook, V. (1949). Lancet, 2, 181. - Bull, J. P., and Jackson, D. M. (1956). Brit. med. F., 1, 1379 Fire Research, 1960, p. 36. H.M.S.O.

Jackson, D. M. (1953). Ann. roy. Coll. Surg. Engl., 13, 236. - (1961). Brit. med. f., 2, 1184.

Lawson, D. I. (1964). Quart. Instn Fire Engrs, 24 (53), 73.

Maisels, D. O., and Corps, B. V. M. (1964). Lancet, 1, 1298.

Registrar-General's Statistical Review of England and Wales, Part 1 , Tables, Medical, for years 1955-62.

Tempest, M. N. (1956). Brit. med. F., 1, 1387.

\title{
Effect of Alcohol on Iron Absorption
}

\author{
R. W. CHARLTON,* M.D., B.SC., M.R.C.P.ED. ; P. JACOBS,* M.B. ; H. SEFTEL, † M.b., B.SC., DIP.MED. \\ T. H. BOTHWELL, * M.D., M.R.C.P.
}

Brit. med. F., 1964, 2, 1427-1429

There are several observations which suggest a relation between excessive consumption of alcohol and the development of iron overload. For example, approximately a third of the patients exhibiting the full-blown clinical manifestations of idiopathic haemochromatosis have a significant alcoholic background (Sheldon, 1935 ; Finch and Finch, 1955). Furthermore, there is evidence that alcoholics as a group tend to have iron siores that are greater than normal (Herbut and Tamaki, 1946 ; MacDonald and Mallory, 1960). Finally, there is suggestive evidence that the severity of the tissue siderosis so commonly noted in the adult Bantu males of South Africa is closely related to the drinking habits of these subjects (Seftel et al., 1961).

There are several possible reasons for these various associations. In the first place, analyses of the home-brewed alcoholic

\footnotetext{
- Department of Medicine, University of the Witwatersrand, Johannesburg, South Africa.

† Baragwanath Hospital, Johannesburg, South Africa.
}

beverages consumed by the Bantu have revealed high iron concentrations (Walker and Arvidsson, 1953), and it has been calculated that many males ingest between 50 and $100 \mathrm{mg}$. of iron daily from this source alone (Bothwell et al., 1964). A similar, though less striking, association between iron and alcoholic intakes has recently been pointed out by MacDonald (1963), who has shown that most European and United States wines contain significant amounts of iron. (For example, the average iron concentration in French wines is $8.8 \mathrm{mg} . / 1$, and in United States wines $4.9 \mathrm{mg}$./1.). A second possible way in which excessive consumption of alcohol may lead to iron overload is through its pathological sequelae, such as chronic pancreatitis and chronic liver disease. Deficiency of the exocrine secretions of the pancreas has been shown to be associated with increased absorption of iron from the gut (Taylor et al., 1931 ; Davis and Badenoch, 1962), and there is recent evidence indicating that some subjects with cirrhosis of the liver absorb iron excessively (Conrad et al., 1962 ; Callender and Malpas, 1963). 